\title{
Direito internacional privado e poder local: a necessária valorização de soluções regionais para conflitos globais
}

Private international law and local power: the necessary valuation of regional solutions to global conflicts

Derecho internacional privado y poder local: la necesaria valorización de soluciones regionales para conflictos globales

Janaina Rigo Santin

Letícia Leidens

\section{Resumo}

O presente artigo, pelo método dialético, problematiza a questão da aplicação do direito internacional privado a conflitos entre cidadãos de países diversos, questionando quais os órgãos de jurisdição internacional cabíveis para a solução desses casos. Entende-se que, em função de sua localização mais próxima aos cidadãos, a Organização dos Estados Americanos pode se mostrar um importante espaço de decisões envolvendo cidadãos latino-americanos, eis que composta por um reduzido número de países que comungam de aspectos identitários comuns, os quais por certo têm melhores condições de conhecer e entender as necessidades locais, as identidades e a cultura dos cidadãos dos países signatários envolvidos no conflito. Quando se trata de direito internacional e órgãos de jurisdição supranacional, entende-se que é preciso valorizar o poder local e as soluções adotadas por órgãos mais próximos dos cidadãos e das nações envolvidas, pois assim estarão sendo valorizadas a cultura, a identidade e a forma de organização regionais, em detrimento de soluções de caráter uniformizador em âmbito global.

Palavras-chave: Direito internacional privado. Organização dos Estados Americanos. Poder local.

Mestre em Direito pela Universidade Federal de Santa Catarina. Doutora em Direito pela Universidade Federal do Paraná, com pós-doutorado em Direito pela Universidade de Lisboa, bolsista Capes. Professora do Mestrado em Direito e do Mestrado e do Doutorado em História da Universidade de Passo Fundo. Professora da graduação da Universidade de Caxias do Sul. E-mail: janainars@upf.br

* Doutora em Direito pela Universidade Gama Filho. Professora de Direito Internacional Privado da Universidade Federal Fluminense. E-mail: lleidens@id.uff.br

Recebido em 29/5/2018 - Aprovado em 21/6/2018 http://dx.doi.org/10.5335/hdtv.18n.3.8596 


\section{Considerações iniciais: globalização e desterritorialização}

Muitos autores buscam conceituar o que é globalização; entretanto, não existe um consenso. A dificuldade se estabelece porque globalização abrange uma série de fenômenos em âmbito mundial, que produzem profundas alterações nas estruturas sociais, econômicas, jurídicas, políticas e culturais, num processo ainda inacabado. Constitui uma tendência dominante, mas que apresenta impactos diferenciados: não é uniforme, não atinge todos os países da mesma forma, nem todos que vivem no mesmo país.

Segundo o entendimento de Antony Giddens (1996, p. 12-13), o processo de globalização não se situa apenas no aspecto econômico, nem deve ser comparado ao surgimento de um "sistema mundial". Trata-se da transformação espacial e temporal; uma ação a distância, intensificada pelo desenvolvimento das tecnologias da comunicação global instantânea, pelo deslocamento mundial de pessoas e pelo transporte em massa. Criam-se sistemas em larga escala de experiência social, transformando realidades locais e até mesmo pessoais. As atividades cotidianas vêm a ser influenciadas por acontecimentos ocorridos em outros locais do planeta. Por sua vez, as pessoas alteram sua residência para outros países, nos quais, por vezes, constroem relações pessoais e profissionais que podem trazer conflitos e repercutir no âmbito do direito internacional privado.

Porém, em reverso, muitas vezes, o mesmo processo fomenta a valorização da cultura, de hábitos e tradições locais, e por isso é também chamado glocalização. Não é, portanto,

[...] um processo único, mas uma mistura complexa de processos, que frequentemente atua de maneira contraditória, produzindo conflitos, disjunções e novas formas de estratificação (GIDDENS, 1996, p. 12-13).

Como no mundo contemporâneo vive-se, em múltiplas escalas ao mesmo tempo, uma simultaneidade atroz de eventos, vivenciam-se também, concomitantemente, múltiplos territórios. Ora somos requisitados a nos posicionar perante uma determinada territorialidade, ora perante outra, como se nossos marcos de referência e controle espaciais fossem perpassados por múltiplas escalas de poder e de identidade. Isto resulta em uma geografia complexa, uma realidade multiterritorial (ou mesmo transterritorial) que se busca traduzir em novas concepções, como os termos cosmopolita e "glocal", este significando que os níveis global e local podem estar quase inteiramente confundidos (HAESBERT; MONDARDO, 2010, p. 19).

A dificuldade para a definição do fenômeno da globalização é reafirmada por Boaventura de Souza Santos, ao dizer que muitos dos signos estão centralizados no aspecto econômico emergente no final do século $X X$, e que se prolonga neste século, em consequência da transnacionalização da produção de bens, serviços e mercado financeiro, bem como pelo deslocamento mundial de pessoas. É resultado de "conjuntos diferenciados de relações sociais", em que não há apenas um conceito ou signo do processo de globalização, sob pena de reducionismo ou fracionamento da realidade, mas há "globalizações", devendo este termo ser usado sempre no plural. Por ser um fenômeno social, as globalizações implicam confli- 
tos, que podem ocorrer nos âmbitos macroeconômico e político, mas também podem ser fomentados no âmbito das relações pessoais entre cidadãos de países diversos. Portanto, Boaventura de Souza Santos propõe a seguinte definição:

[...] globalização é o processo pelo qual determinada condição ou entidade local estende a sua influência a todo o globo e, ao fazê-lo, desenvolve a capacidade de designar como local outra condição social ou entidade rival (SANTOS, 2005, p. 21).

Outra consideração fundamental é que tanto o processo produtivo como as informações e a circulação financeira globalizam-se e fragmentam-se; porém, os instrumentos de regulação continuam no âmbito do Estado nacional.

Há um grande

[...] descompasso entre a rapidez da evolução das técnicas e a relativa lentidão das transformações institucionais, gerando um amplo espaço econômico mundial sem nenhum controle ou regulação, e uma perda global de governabilidade no planeta [pelas instituições modernas tradicionais] (DOWBOR, 1996, p. 57-58).

Adotando-se a analogia utilizada por Ladislau Dowbor, esta dramática diferença “[...] nos coloca como que no comando de um imenso avião moderno, tendo no painel os modestos controles de um fusca" (1998, p. 10, grifo do autor).

Com a globalização, ocorre uma remodelação das fronteiras nacionais e das relações entre indivíduos, que se tornam desterritorializadas. Assim, visualizar a globalização não é tarefa fácil, pois ela se apresenta multifacetada e irregular. Caracterizações maniqueístas não são capazes de descrevê-la, já que não se submete a conceitos fechados nem a posições absolutas. ${ }^{1}$

Renato Ortiz (1996) também descreve o fenômeno da globalização como um processo emergente, ainda em construção. Difere globalização da internacionalização, tendo em vista que esta trata da ampliação geográfica das atividades econômicas por intermédio dos Estados nacionais; enquanto aquela consiste em uma etapa mais avançada e complexa da internacionalização, integrando de modo funcional atividades econômicas dispersas. A partir de tais constatações, o autor aplica o conceito às esferas produtiva, de distribuição e consumo de bens e serviços, que passam a ser organizadas em estratégias de alcance mundial, voltadas ao mercado internacional. Trata-se de "[...] um nível e uma complexidade da história econômica, no qual as partes, antes inter-nacionais se fundem agora numa mesma síntese: o mercado mundial" (ORTIZ, 1996, p. 15-16).

Antônio Rodrigues de Freitas Júnior (1997, p. 206) salienta que é preciso separar a globalização geral da econômica e da jurídico-política, considerando que o processo de globalização, quando visto como fenômeno jurídico-político, foi provocado a partir da globalização econômica.

O autor apresenta a seguinte diferenciação:

a) globalização geral é um:

[...] fenômeno social, consistente na aproximação de distâncias geográficas e na homogeneização das expectativas de consumo, de imaginários culturais e de práticas políticas, decorrente da globalização econômica (FREITAS JÚNIOR, 1997, p. 206); 
b) globalização econômica é um fenômeno econômico caracterizado pela:

[...] internacionalização dos mercados de bens, serviços e créditos, induzida pela redução de tarifas de exportação, de obstáculos aduaneiros, e pela padronização das operações mercantis, resultando na fragmentação e na dispersão internacional das etapas do processo produtivo (FREITAS JÚNIOR, 1997, p. 206);

c) globalização jurídico-política consiste no:

[...] deslocamento da capacidade de formulação, de definição e de execução de políticas públicas, antes radicada no Estado-Nação, para arenas transnacionais ou supranacionais (FREITAS JÚNIOR, 1997, p. 206).

E isso surte efeitos diretos sobre o alcance do poder soberano nacional. ${ }^{2}$

Para MichelChossudovsky (2004, p. 20), inaugura-se uma "nova divisão de autoridade", agora nas mãos de instituições que agem em caráter supranacional, operando como órgãos reguladores das relações entre países e entre seus nacionais também.

Grande parte dos conceitos, das categorias e das leis formuladas na modernidade pelas ciências sociais foi baseada em "relações, processos e estruturas de dominação e apropriação, integração e antagonismo, soberania e hegemonia" (IANNI, 1997, p. 90), características do Estado nacional. O paradigma clássico das ciências sociais foi construído e está alicerçado na sociedade nacional, povoando o imaginário dos cientistas sociais e de escolas de pensamento. É reproduzido em manuais, universidades, centros de pesquisa, revistas especializadas, livros, ensaios, monografias, teses e dissertações.
Todavia, esse conceito de soberania nacional, definido no limiar da consolidação do Estado moderno, com o fim do monopólio da representação internacional da nação, passa a ser relativizado. Nos últimos anos, novos atores ou centros de poder são reconhecidos no cenário mundial, com capacidade de influência maior que a maioria dos Estados-Nação. ${ }^{3}$ Esses novos centros de poder dispõem de " [...] objetivos e meios, recursos e interpretações, para decidir e atuar, induzir e impor, por sobre e além dos governos e fronteiras" (IANNI, 1996, p. 138); detêm um incrível poder de ação sobre os indivíduos nos âmbitos local, regional, nacional e global. ${ }^{4}$

Tais transformações epistemológicas originam discussões sobre dois enfoques: a humanidade está caminhando para uma fase de pós-modernidade ou transmodernidade, na qual as instituições da modernidade estão sendo substituídas por uma nova e diferente ordem social (WARAT, 1996; SANTOS, 2001); $;^{5}$ ou apenas está diante de uma fase de radicalização da modernidade.

Antony Giddens (1991, p. 56-57) filia-se ao segundo entendimento, afirmando tratar-se de um equívoco definir tais transformações como pós-modernidade. Configuram-se, pois, de disjunções resultantes "da autoelucidação do pensamento moderno", descartando-se reminiscências da tradição e da providência. Não há um deslocamento do paradigma para além da modernidade; há uma radicalização da própria modernidade. ${ }^{6}$

David Held (1991) ratifica tal posição ao constatar que a ordem internacional, e com ela o papel do Estado-Nação, enfrenta um processo de mudança, já que opera em um sistema internacional complexo, no qual 
os Estados nacionais convivem com instâncias supranacionais de definição de tutelas jurídicas e políticas, em âmbito do direito internacional tanto público quanto privado. $\mathrm{O}$ autor, portanto, coloca em questão toda e qualquer concepção de soberania nacional extraída em moldes ilimitados e indivisíveis (HELD, 1991, p. 178). O Estado-Nação é obrigado a compartilhar ou a aceitar decisões e diretrizes provenientes de outros centros de poder, de escala global, que pairam além das soberanias nacionais, num surpreendente processo de desterritorialização, ${ }^{7}$ porque tanto a economia quanto a cultura, a política, os indivíduos e a sociedade estão desterritorializados.

\section{Direito internacional privado e organizações decisórias internacionais}

Neste processo multifacetado de globalização, o presente artigo dará ênfase às questões relacionadas à circulação de pessoas entre diferentes nações e às formas de solução dos conflitos advindo dessas relações. Para tanto, mostra-se apto o ramo do direito internacional privado, no qual se estabelecem algumas organizações internacionais de solução de conflitos, em âmbito regional, como a Corte Interamericana de Direitos Humanos e a Corte Europeia de Direitos Humanos, bem como em âmbito global, como a Corte Internacional de Justiça. Também, no âmbito normativo, a produção de instrumentos que respondam aos problemas transnacionais de circulação de pessoas aparece como um conteúdo de extrema relevância para o direito internacional e para a comunidade internacional.
Nesse sentido, pode-se citar a Organização da Haia ${ }^{8}$ como relevante organização na produção convencional, inclusive com êxito nos trabalhos pós-convencionais, visando trabalhar na perspectiva da uniformidade entre os países, no trato tanto legislativo quanto jurisprudencial. Os usos de critérios utilizados pelas diferentes realidades servem para o auxílio na formação das premissas aplicativas. Em paralelo, é aplicada a orientação estipulada pela Convenção de Viena do Direito dos Tratados de 1969, nos artigos 31 e 33, que ratifica um caminho em prol da interpretação e da aplicação dos tratados de acordo com seus fins. Além disso, em eventual discordância conceitual acerca dos termos nas línguas originais e traduzidas, nenhuma deve prevalecer em detrimento de outra (GEBAUER, 2000, p. 45). É necessário analisar o sentido do objeto de investigação e os objetivos do tratado, para conciliar as questões postas.

Na América Latina, em especial no Brasil, destaca-se o recorrente uso das convenções da Haia para solução de conflitos transnacionais, em detrimento do uso das convenções produzidas na Organização dos Estados Americanos (OEA), no âmbito regional. Evidentemente, uma das razões de tal disparidade reside no reduzido número de países contratantes no âmbito regional, no entanto, no trato do conteúdo, a produção legislativa é muito similar entre Haia e OEA. Dessa forma, pensa-se que, quando se tratar de um conflito transnacional que envolva países membros da OEA e que ratificaram uma convenção internacional em comum, não há razões para sua inaplicabilidade, valorizando-se o espaço regional ou local de solução dos conflitos. A percepção que se justifica perpassa pelo cenário cultural, inclu- 
sive com o trato do direito internacional, eis que, na prática jurisprudencial, as diferenças do uso entre as convenções oriundas da OEA e da Haia são alarmantes.

A utilização das convenções interamericanas pelo sistema brasileiro mostra-se inexpressivo. Destaca-se o tema de subtração internacional de menores, o qual vem sendo objeto de considerável quantitativo da cooperação internacional ativa e passiva no sistema brasileiro contemporâneo. Nesse contexto, a presença de crianças nessas relações agrava o quadro conflituoso e trava a necessidade de se garantir a sua tutela no plano internacional, mediante a predisposição de instrumentos jurídicos que assumam a prevenção dos efeitos indesejáveis que possam causar na sociedade. ${ }^{9}$

O Brasil ratificou a convenção sobre aspectos civis do sequestro internacional de crianças de 1980, da Haia, bem como a convenção sobre subtração internacional de menores da OEA. A Convenção Interamericana de Restituição Internacional de Menores foi um dos resultados da IV Conferência Especializada Interamericana sobre Direito Internacional Privado (CIDIP) de Montevidéu, realizada em 1989 no Uruguai, a qual foi internalizada pela República Federativa do Brasil por meio do Decreto $n^{0}$ 1.212/1994. No que se refere ao paralelo das estruturas normativas da Convenção Interamericana e da Convenção de Haia, ambas trabalham na mesma perspectiva, a fim de tutelar crianças subtraídas ilicitamente, utilizando a nomenclatura para o ato de subtração, consistente no ato de transferência e retenção.

A Convenção Interamericana, já no seu título, opta por utilizar o termo menor, e não criança; prevendo, no seu artigo $2^{\circ}$, o limite de 16 anos para fins de aplicabilidade convencional. Além disso, agrega o direito de custódia ao lado do direito de guarda como instituto similar. No que concerne às exceções à ordem de retorno, a Convenção Interamericana prevê, no seu artigo 11, somente três hipóteses normativas, consistentes ao consentimento posterior do genitor(a) com a subtração ilícita; grave risco de expor a criança a perigos de ordem física e psíquica; oposição da criança com idade e maturidade a serem consideradas.

Assim, verifica-se que o campo normativo das exceções foi reduzido em comparação à Convenção de Haia. O elemento distintivo reside no seu artigo 34, que dispõe:

[...] esta Convenção vigorará para os Estados membros da Organização dos Estados Americanos, partes nesta Convenção e no Convênio de Haia, de 25 de outubro de 1980, sobre os aspectos civis do sequestro internacional de menores. Entretanto, os Estados Partes poderão convir entre si, de forma bilateral, na aplicação prioritária do Convênio de Haia de 25 de outubro de 1980 (OEA, 1989, não paginado).

Logo na primeira parte do dispositivo, a convenção se coloca como prioridade entre os Estados-Membros da OEA, já na segunda parte do dispositivo, é facultado aos Estados a definição prioritária. Isso porque o seu artigo 30 estabelece que a convenção é aberta à adesão de qualquer outro Estado, ainda que não seja membro da organização. Isso dá à Convenção Interamericana condições mais amplas que as da Convenção de Haia, pois ela determina, no seu artigo 38, que os efeitos da adesão se limitam nas relações entre Estado aderente e Estados contratantes que tenham declarado sua aceitação da adesão, 
ainda que se verifique na prática outro direcionamento. O importante é que os documentos não são excludentes, ao contrário, $\mathrm{o}$ fomento está incorporado na norma convencional interamericana, já que foi criada posteriormente.

Em verificação no plano jurisprudencial brasileiro, a Convenção Interamericana é citada ao lado da Convenção de Haia, no entanto, não é aplicada a rigor. Os motivos da ocorrência, por parte da doutrina, se restringem na extensão, regionalizada que possui, a priori, bem como no reduzido número de hipóteses dos artigos, exceções que afastariam a ordem de retorno da criança ao Estado de residência habitual.

De todo modo, buscou-se fomentar a discussão acerca da adesão aplicativa convencional no plano regional, principalmente em se tratando da temática que envolve a criança no plano internacional, a fim de aperfeiçoar o sistema regionalizado em detrimento do global. Isso porque, como se verificou, não se tratam de diferenças de tratamento do conteúdo jurídico propriamente dito, mas de um fenômeno cultural. O que se pretende é impulsionar o seu uso, quando verificada a aproximação dos sistemas internacionais e da tutela semelhante, senão idêntica, para resolver conflitos transnacionais. De todo modo, tratam-se de organismos que reúnem representações da maioria dos países mundiais, a fim de discutir questões jurídicas, políticas, econômicas, sociais e culturais relativas aos cidadãos integrantes dos países signatários.

\section{Poder local:judicialização e identidade local}

Conforme evidenciado anteriormente, os processos de globalização e de internacionalização das relações econômicas, jurídicas, culturais, políticas e sociais abalam todo o modelo institucional tecido na modernidade. E, nesse sentido, a própria noção de cidadania encontra-se em mutação, ultrapassando as fronteiras nacionais, ainda que com sentidos e intenções diferenciados. ${ }^{10}$ Sem dúvida, essa noção contemporânea de cidadania deriva dos movimentos sociais, engendradores de uma nova maneira de inserção de espaços para ascensão dos cidadãos aos meios de participação previstos e, com isso, para intervenção nos rumos estatais. ${ }^{11}$

A construção dessa visão de cidadania aponta para a difusão de uma nova cultura democrática, potencializadora do crescimento da participação cidadã e da valorização das soluções advindas do espaço local. A democracia representa a distribuição de poder político aos cidadãos, os quais passam a ter a possibilidade de concretizar o sonho de "fazer parte" das decisões que dizem respeito a si e aos setores políticos e de poder nos quais se inserem (CAPILONGO, 2000, p. 105). A nova cidadania luta pela própria noção de direitos, ou seja, luta pelo direito a ter direitos (DAGNINO, 1994; COMPARATO, 1993). Essa concepção não se limita às conquistas legalmente previstas ou ao acesso a direitos definidos com antecedência, mas inclui a invenção de novos direitos emergentes das experiências concretas dos movimentos sociais e das interações entre indivíduos e grupos de diversos estados, para as quais o 
direito internacional privado precisa trazer respostas legítimas e capazes de se chegar a um grau mínimo de consenso entre os países de origem dos cidadãos em conflito.

A concretização dessa nova cidadania vem a ser impulsionada por uma tendência de reorganização dos espaços do próprio direito internacional. Busca-se valorizar as soluções que venham de órgãos multilaterais mais próximos dos cidadãos envolvidos no conflito, revitalizando o âmbito local ou regional, e fazer com que as decisões tomadas pelas instituições internacionais de solução de conflitos possam se aproximar da realidade e da cultura dos cidadãos neles envolvidos.

O poder local, tão suscitado nos tempos atuais, trata-se de locus privilegiado para que a sociedade e os países transfronteiriços cujos conflitos apresentam noções identitárias mais próximas possam tomar as rédeas de seu próprio desenvolvimento. Nas palavras de Ladislau Dowbor,

[...] esta rearticulação passa por uma redefinição da cidadania, e em particular por uma redefinição das instituições para que os espaços participativos coincidam com as instâncias de decisões significativas. As hierarquizações tradicionais dos espaços já são insuficientes, ou inadequadas; precisamos de muito mais democracia, de uma visão mais horizontal e interconectada da estrutura social (1996, p. 73).

Fica claro que a característica maior do poder local é atingir a descentralização do poder e a divisão do poder decisório com os representados. No entendimento de Jordi Borja e Manuel Castells (1997), em um mundo globalizado, ante a crise estrutural, de competências e de poder em que se en- contram os Estados nacionais, os governos locais recebem um papel político revitalizado. Em suma, os Estados passam a ser muito pequenos para controlar e dirigir os fluxos globais de poder, riqueza e tecnologia; e, ao contrário, muito grandes para representar a pluralidade de interesses sociais e identidades culturais da sociedade (BORJA; CASTELLS, 1997, p. 12-20).

Nessas condições, as instituições regionais e supranacionais de solução de litígios, como a Organização dos Estados Latino-Americanos, emergem em todo o mundo como entidades mais flexíveis que o Estado-Nação e mais próximas dos seus signatários que as entidades multilaterais mais amplas, como a jurisdição internacional. São capazes de negociar uma adaptação contínua na geometria variável dos fluxos de poder dos países envolvidos, sem perder suas identidades e culturas. Entretanto, sabe-se que a dificuldade enfrentada pelos governos locais é sua dependência administrativa em algumas áreas aos órgãos centrais e, em especial, sua escassa capacidade de obter efetivação de suas decisões. O que se percebe é que os países latino-americanos estão utilizando como meio de solução de conflitos cortes internacionais, caracterizadas como mais amplas, como a Corte Interamericana de Direitos Humanos e a Corte Internacional de Justiça de Haia, em detrimento das soluções locais, que poderiam trazer maiores aspectos identitários regionalizados, como é o caso da OEA.

Assim, a reconstrução de um modelo de direito internacional mais próximo das identidades e da cultura locais passa por uma nova perspectiva na gestão dos con- 
flitos de direito internacional. Valorizar as instâncias locais de solução de conflitos. Por certo, ao se aproximarem os órgãos decisórios das pessoas e dos países diretamente envolvidos com os conflitos, possibilitar-se-á uma decisão mais eficiente, capaz de valorizar as identidades e a cultura locais e, por isso, mais voltada às necessidades da população e dos países envolvidos. Potencializa-se uma democracia de proximidade, de participação de todos na gestão da coisa pública e de reforço das identidades coletivas. E, nesse sentido, democracia local é cidadania (BORJA; CASTELLS, 1997, p. 363-373).

Diante desses fatores, é nítida a possibilidade de descentralização e participação por parte dos cidadãos mediante a efetiva implementação desta categoria sociológica denominada "poder local", ${ }^{12}$ compreendida, neste trabalho, como um novo paradigma de legitimação da jurisdição internacional.

Com a aproximação dos órgãos decisórios e das pessoas e das nações diretamente afetadas por tais decisões, a chance de acerto é muito maior. Por certo, os países latino-americanos possuem aspectos identitários comuns, que os unem de uma maneira muito mais forte que países de outros continentes. E, por isso, é importante valorizar as decisões de direito internacional tomadas pela OEA, em detrimento das decisões tomadas em âmbito global, como a Organização das Nações Unidas (ONU) e os centros de estudos de direito internacional privado, como Haia, já que há um número muito maior de países signatários, com uma maior diversidade de cultura, política, religião e sistemas jurídicos.

Um autor que enfatiza a necessidade de aproximar os julgadores das pessoas di- retamente envolvidas nas decisões é Jürgen Habermas, quando formula a sua proposta de procedimento democrático de elaboração do direito. Nesse sentido, entende-se pela possibilidade da aplicação da teoria do discurso dentro dos mecanismos decisórios mais regionalizados, como a Organização dos Estados Latino-Americanos. Mediante o complexo comunicacional dali advindo, passam as nações signatárias e as pessoas envolvidas nos conflitos a determinar suas relações e a definir juridicamente as condições em que elas deverão ocorrer, sendo tanto atores quanto destinatários das decisões jurídico-políticas (HABERMAS, 1997).

Habermas (1997) descreve, por exemplo, as questões de gênero, para as quais deve-se abordar a partir de uma perspectiva comunicacional desenvolvida na esfera pública das instituições regionais de solução de conflitos, e não em um espaço mais amplo como Haia, no qual convivem diversos países, com culturas díspares. Para o autor, é preciso aproximar os envolvidos nas deliberações a respeito de conflitos que lhes digam respeito, para que não se adotem decisões errôneas, como afirmar que as mulheres devem seguir o mesmo caminho dos homens para conquistar direitos iguais. Em verdade, a solução para os problemas femininos deverá ser dada mediante discussões públicas, desenvolvidas pelos próprios afetados, eis que a compreensão adequada do papel do gênero e das suas diferenças varia conforme o tempo e o espaço. Logo, deve-se proporcionar aos atingidos a efetiva possibilidade de "levantar a sua voz e exigir direitos", a partir de experiências concretas de lesão da integridade de seus direitos, bem como de desfavorecimen- 
to e de opressão, situação que não poderá ser delegada a juízes, a funcionários ou ao legislador político. Logo,

[...] nenhuma regulamentação, por mais sensível que seja ao contexto, poderá concretizar adequadamente o direito igual a uma configuração autônoma da vida privada, se ela não fortalecer, ao mesmo tempo, a posição das mulheres na esfera pública política, promovendo a sua participação em comunicações políticas, nas quais é possível esclarecer aspectos relevantes para uma posição de igualdade (HABERMAS, 1997, p. 168).

Para o autor, a concepção procedimental é incompatível tanto com a ideia kelseniana de que a lei positiva pode retirar sua legitimidade de uma lei mais elevada, quanto com a noção positivista da inexistência de qualquer outra forma de legitimidade que não a lei. Ou seja, o direito positivo não pode mais derivar sua legitimidade de uma lei moral mais elevada, mas apenas de um procedimento racional de formação de opinião e vontade, à luz do princípio do discurso, capaz de possibilitar aos cidadãos testarem entre si quais direitos e atos administrativos devem conceder-se mutuamente, numa espécie de autolegislação (HABERMAS, 1997). Dessa maneira, resolve-se o problema de legitimação do direito internacional e dos órgãos multilaterais de decisão mediante a força produtiva da comunicação, da negociação equitativa de compromissos e da formação discursiva da vontade, as quais acontecem no locus da esfera pública local, que no caso do Brasil seria a OEA.

\section{Consideraçōes finais}

Em função de sua localização mais próxima aos cidadãos, a OEA pode se mostrar um importante espaço de decisões supranacionais, pois é composta apenas dos países latino-americanos, que têm melhores condições de conhecer e entender as necessidades locais, as identidades e a cultura dos cidadãos dos países signatários.

Nas palavras de Jürgen Habermas,

[...] o processo democrático da criação do direito constitui a única fonte pós-metafísica da legitimidade. No entanto, é preciso saber de onde ele tira sua força legitimadora. A teoria do discurso fornece uma resposta simples, porém inverossímil à primeira vista: o processo democrático, que possibilita a livre flutuação de temas e de contribuições, de informações e de argumentos, assegura um caráter discursivo à formação política da vontade, fundamentando, deste modo, a suposição falibilista de que os resultados obtidos de acordo com esse procedimento são mais ou menos racionais (1997, p. 170).

Por meio do direito, há um transporte das estruturas reconhecidas de modo recíproco pelo agir comunicativo nos espaços públicos para as interações sociais entre estranhos, mediadas pelo sistema nas esferas públicas. Ou seja, ao se utilizar de órgãos jurisdicionais regionalizados, apesar de supranacionais, é possível transportar a cultura e as formas de regulação dos países latino-americanos. Assim, a legitimação do sistema de jurisdição supranacional virá da ideia de autodeterminação, na qual as pessoas e as nações envolvidas enxergar-se-ão como autoras de uma decisão jurisdicional mais próxima da sua realidade, da sua cultura e 
das suas necessidades, ao qual estão submetidas como destinatárias; são "participantes em processos de entendimento que versam sobre as regras de sua convivência". Por conseguinte, será mais fácil impor politicamente as decisões legais e administrativas, já que os afetados por elas terão a possibilidade de as discutir publicamente, mobilizando o poder comunicativo para considerar as necessidades de modo novo.

À luz do princípio do discurso, nas esferas supranacionais de jurisdição, como a OEA, os sujeitos examinam quais os direitos que eles deveriam conceder-se mutuamente. Dessa forma, há uma alteração do modelo do contrato social, o qual

[...] é substituído por um modelo do discurso ou da deliberação: a comunidade jurídica não se constitui através de um contrato social, mas na base de um entendimento obtido através do discurso (HABERMAS, 1997, p. 308-310).

Logo, "[...] o princípio do discurso assume a figura jurídica de um princípio da democracia" (HABERMAS, 1997, p. 321).

Assim, quando se fala em direito internacional e órgãos de jurisdição supranacional, entende-se que é preciso valorizar o poder local e as soluções adotadas por órgãos mais próximos dos cidadãos e das nações envolvidas, pois assim estarão sendo valorizadas a cultura, a identidade e a forma de organização regionais, em detrimento de soluções de caráter uniformizador em âmbito global.

\section{Abstract}

This article, through the dialectical method, questions the question of the application of private international law to conflicts between citizens of different countries, questioning which bodies of international jurisdiction are available to solve these cases. It is understood that, because of its location closer to the citizens, the Organization of American States can show itself to be an important decision space involving Latin American citizens, since it is composed of a small number of countries that share common identities, which are certainly better able to know and understand the local needs, identities and culture of the citizens of the signatory countries involved in the conflict. When speaking about international law and bodies of supranational jurisdiction, it is understood that it is necessary to value Local Government and the solutions adopted by organs closer to the citizens and nations involved, as this will be valuing the culture, identity and form of regional organizations, to the detriment of uniform solutions at the global level.

Keywords: Private international law. Organization of American States. Local power. 


\section{Resumen}

El presente artículo, por el método dialéctico, problematiza la cuestión de la aplicación del derecho internacional privado a conflictos entre ciudadanos de países diversos, cuestionando cuáles son los órganos de jurisdicción internacional adecuados para la solución de estos casos. Se entiende que, en función de su ubicación más cercana a los ciudadanos, la Organización de los Estados Americanos puede mostrar un importante espacio de decisiones que involucra a ciudadanos latinoamericanos, que compuesta por un reducido número de países que comulgan de aspectos identitarios comunes, que por cierto tienen mejores condiciones de conocer y entender las necesidades locales, las identidades y la cultura de los ciudadanos de los países signatarios involucrados en el conflicto. Cuando se habla de derecho internacional y órganos de jurisdicción supranacional, se entiende que es necesario valorar el poder local y las soluciones adoptadas por órganos más cercanos a los ciudadanos y naciones implicadas, pues así se va valorizando la cultura, la identidad y la forma organización regional, en detrimento de soluciones de carácter uniformizador a nivel global.

Palabras clave: Derecho internacional privado. Organización de los Estados Americanos. Poder local.

\section{Notas}

1 Ressalta-se a posição de Paulo Nogueira Batista Jr., denunciando que a globalização é um mito apoiado em meias-verdades, a fim de "[...] paralisar as iniciativas nacionais, que passam a ser rotuladas como ineficazes, sem maior discussão". Passa a ser utilizada como "[...] desculpa para tudo, uma explicação fácil para o que acontece de negativo no país. Governos fracos e omissos servem-se dessa retórica para isentar-se de responsabilidade, transferindo-a para um fenômeno impessoal e vago, fora do controle nacional. [...] Em suma, problemas como o desemprego e o subemprego, a desnacionalização da economia e a dependência de capitais externos, longe de constituírem a conseqüência irrecorrível de um processo global, resultam essencialmente de políticas adotadas no âmbito nacional, convenientemente dissimuladas pelo apelo à retórica da 'globalização'". Entende-se que globalização significa internacionalização, na qual se reproduzem em âmbito mundial as relações de dominação dos Estados capitalistas avançados e do mercado (BATISTA JÚNIOR, 1998, p. 125-129). Tal posição é acentuada na obra de Hirst e Thompson (1996).

2 Octavio Ianni descreve as características do processo de globalização: "Primeiro, a energia nuclear tornou-se a mais poderosa técnica de guerra; inicialmente mobilizada pelas grandes potências mas, em seguida, já disponível nas mãos de dirigentes de nações de segundo e terceiro escalão. Segundo a revolução informática baseada nas conquistas da eletrônica coloca nas mãos dos donos do poder - outra vez dos países dominantes, mas também de outros secundários - uma capacidade excepcional de formar e informar, induzir e seduzir, talvez jamais alcançada anteriormente na mesma escala. Terceiro, organiza-se um sistema financeiro internacional, em conformidade com as exigências da economia capitalista mundial e de acordo com as determinações dos países dominantes, tais como os Estados Unidos, o Japão e a Alemanha, bem como a Comunidade Econômica Européia, o Grupo dos 7 e as determinações do Fundo Monetário Internacional (FMI) e do Banco Internacional de Reconstrução e Desenvolvimento (BIRD), ou Banco Mundial. Quarto, as relações econômicas mundiais, compreendendo a dinâmica dos meios de produção, das forças produtivas, da tecnologia, da divisão internacional do trabalho e do mercado mundial, são amplamente influenciadas pelas exigências das empresas, corporações ou conglomerados 
multinacionais, transnacionais, mundiais, globais, planetários. Quinto, a reprodução ampliada do capital, compreendendo a concentração e a centralização de capitais, universaliza-se na realidade em nova escala, com novo ímpeto, recriando relações nos quatro cantos do mundo, pressionando as nações socialistas, influenciando, bloqueando ou rompendo os seus sistemas econômicos. Sexto, o inglês se transforma na língua universal, uma espécie de língua franca, por meio da qual se articulam e expressam indivíduos, grupos e classes, em países dominantes e dependentes, centrais e periféricos, tribais e clânicos, oligárquicos e democráticos, capitalistas e socialistas, em suas relações sociais, políticas, econômicas e culturais. Sétimo, o ideário do neoliberalismo adquire predomínio mundial, como ideologia e prática, modo de compreender e agir, forma de gestão do mercado e poder político, concepção do público e privado, ordenação da sociedade e visão do mundo" (IANNI, 1996, p. 58-59).

3 Octavio Ianni justifica tais transformações pelo caráter dinâmico da sociedade e do Estado-Nação, que é um produto social e, portanto, sujeito às contingências humanas, pois sempre foi desafiado pelo jogo das forças sociais internas e externas, sob distintos regimes políticos, conforme o interesse do bloco de poder que se encontra no comando (IANNI, 1997, p. 92-95, 263; 1996, p. 39-43).

4 Para maior aprofundamento sobre o assunto, ver Santin (2009, p. 79-92).

5 Jürgen Habermas aponta que a fase de crise que o Estado nacional enfrenta no início do século XXI marca uma fase "para além do Estado nacional", a qual ele denomina "constelação pós-nacional", tendo em vista os impulsos de desnacionalização de uma sociedade mundial inaugurada pelo âmbito econômico (HABERMAS, 2001, p. 158).

6 Num entendimento semelhante, Peter Drucker afirma que estamos numa sociedade "pós-capitalista", na qual "[...] a ordem mundial de ontem está indo embora depressa, enquanto a de amanhã ainda não emergiu. Na verdade, não estamos enfrentando 'a nova ordem mundial' invocada com tanta frequência pelos políticos. Ao contrário, estamos enfrentando uma nova desordem mundial - por quanto tempo, ninguém pode saber. Em estrutura política e também na forma de governo estamos entrando em uma era 'pós', a era do estado pós-soberano. Já conhecemos as novas forças - e elas são bastante diferentes daquelas que governaram a estrutura política e a forma de governo pelos últimos quatrocentos anos. Conhecemos as novas demandas e podemos delinear algumas, talvez a maioria. Entretanto, não conhecemos as respostas, as soluções, as novas integrações" (DRUCKER, 2002, p. 81).

7 Sobre o conceito de desterritorialização, ver Ianni (1996, p. 93-94).

8 A conferência realizou-se em 1893, com a participação de 13 delegações europeias e, a partir dessa reunião, Haia passou a ser a sede da Conferência de Direito Internacional Privado. A partir de 1951, consolidou-se como organização internacional, teve grande impulso no final do século XIX. Nos últimos anos, algumas convenções da Haia adotam regras de conflito de caráter substancial, por meio de diversas técnicas, estabelecendo regras com vínculos alternativos, subsidiários ou cumulativos (ARAÚJO, 2018, p. 78).

9 Ainda que tantas possam ser as referências do conceito de direito, a teoria do direito contemporânea tem primado por um conceito um tanto mais pluralista e interdisciplinar possível, sem renegar seus laços de historicidade e cientificidade. Destacam-se as palavras de Andrieu: “O direito é, portanto, o conjunto dos modos como esses textos são produzidos, as maneiras pelas quais são lidos, as instituições que os produzem, zelam por sua leitura e sua tradução em atos da vida corrente (relações familiares, contratuais, administração da vida pública, gestão da propriedade) ou em atos de controle dos desvios, transgressões e disfunções. Mas o direito não pode resumir-se aos edifícios, o mais das vezes estatais, construídos sobre os textos. Pode ser mais amplamente considerado como a maneira pela qual um grupo, uma cultura, eventualmente sem escrita, reúne os instrumentos necessários para realizar a obra jurídica, ou seja: prevenir $e$ tratar os conflitos que venham a surgir na sociedade em nome de uma referência compartilhada. Essa concepção ampliada desvela uma paisagem panorâmica, cumprir além dos códigos, das palavras e das interpretações dadas pelos juízes de toga ou de peruca e ver o jurídico fora de sua encarnação do Estado. Voltamo-nos, então, para os fatos tangíveis da vida social bruta em que se expressa, tão claramente como na forma erudita, um sentido particular do justo e do injusto, do possível e do proibido, do que é e do que deve ser o direito" (ANDRIEU, 2000, p. 16-17).

10 Sobre a noção clássica de cidadania, ver Marschall (1967).

11 Boaventura de Souza Santos indica um novo modelo de democracia participativa derivada dos movimentos sociais como estratégia de oposição à trivialização da cidadania e à exclusão social, 
mediante modalidades de produção não capitalistas. Para aprofundamento do tema, ver Santos (2002).

12 Para um aprofundamento da temática do poder local, ver Santin (2017).

\section{Referências}

ANDRIEU, Louis Assier. O direito nas sociedades humanas. Trad. Maria Hermantina Galvão. São Paulo: Martins Fontes, 2000.

ARAÚJO, Nádia. Direito internacional privado - teoria e prática. São Paulo: Revista dos Tribunais, 2018.

BATISTA JÚNIOR, Paulo Nogueira. Mitos da "globalização". Estudos Avançados, São Paulo: USP, v. 12, n. 32, p. 125-129, 1998.

BORJA, Jordi; CASTELLS, Manuel. Local y global: la gestión de las ciudades en la era de la información. Madrid: Taurus, 1997.

CAPILONGO, Celso Fernandes. Direito e democracia. 2. ed. São Paulo: Max Limonad, 2000.

CHOSSUDOVSKY, Michel. A globalização da pobreza: impactos das reformas do FMI e do Banco Mundial. Trad. Marylene Pinto Michael. São Paulo: Moderna, 2004.

COMPARATO, Fábio Konder. A nova cidadania. Revista Lua Nova, São Paulo, n. 28-29, p. 85-106, 1993.

DAGNINO, Evelina (Org.). Anos 90: política e sociedade no Brasil. São Paulo: Brasiliense, 1994.

DOWBOR, Ladislau. Da globalização ao poder local: a nova hierarquia dos espaços. In: FREITAS, Marcos Cézar de (Org.). A reinvenção do futuro. São Paulo: Cortez; Bragança Paulista: USF-IFAN, 1996. p. 107-154.

. Globalização e tendências institucionais. In: DOWBOR, Ladislau; IANNI, Octavio; RESENDE, Paulo-Edgar A. (Org.). Desafios da globalização. Petrópolis: Vozes, 1998. p. 53-87.
DRUCKER, Peter. Sociedade pós-capitalista. Trad. Nivaldo Montingelli Jr. São Paulo: Pioneira Thomson Learning, 2002.

FREITAS JÚNIOR, Antônio Rodrigues de. Globalização \& integração regional: horizontes para o reencantamento do direito do trabalho num quadro de crise do Estado-Nação. Revista LTr, São Paulo, v. 61, n. 2, p. 205-213, fev. 1997.

GEBAUER, Martin. Uniform law, general principles na autonomous interpretation. Uniform Law Review, v. 5, n. 4, p. 683-704, Dec. 2000.

GIDDENS, Anthony. As conseqüências da modernidade. Trad. Raul Fiker. São Paulo: Unesp, 1991.

. Para além da esquerda e da direita. Trad. Alvaro Hattnher. São Paulo: Unesp, 1996.

HABERMAS, Jürgen. A constelação pós-nacional: ensaios políticos. Trad. Márcio Seligmann-Silva. São Paulo: Littera Mundi, 2001.

. Direito e democracia: entre facticidade e validade. v. 2. Trad. Flávio Beno Siebeneichler. Rio de Janeiro: Tempo Brasileiro, 1997.

HAESBERT, Rogério; MONDARDO, Marcos. Transterritorialidade e antropofagia: territorialidades de trânsito numa perspectiva brasileira-latino-americana. Revista GEOgraphia, Niterói, v. 12, n. 24, p. 19-50, 2010.

HELD, David. A democracia, o estado-nação e o sistema global. Revista de Cultura e Política Lua Nova, São Paulo, n. 23, p. 145-194, mar. 1991.

HIRST, Paul; THOMPSON, Grahame. Globalization in question: the international economy and the possibilities of governance. Cambridge: Polity Press, 1996.

IANNI, Octávio. A era do globalismo. Rio de Janeiro: Civilização Brasileira, 1997.

. A sociedade global. 4. ed. Rio de Janeiro: Civilização Brasileira, 1996. 
MARSCHALL, T. H. Cidadania, classe social e status. Trad. Meton Porto Gadelha. Rio de Janeiro: Zahar, 1967.

ORGANIZAÇÃO DOS ESTADOS AMERICANOS. Convenção Interamericana sobre a Restituição Internacional de Menores. 1989. Disponível em: <http://www.oas.org/juridico/ portuguese/treaties/b-53. htm>. Acesso em: 10 maio 2018.

ORTIZ, Renato. Mundialização e cultura. 2. ed. São Paulo: Brasiliense, 1996.

SANTIN, Janaína Rigo. As novas fontes de poder no mundo globalizado e a crise de efetividade do direito. Revista da Seção Judiciária do Rio de Janeiro, Rio de Janeiro, n. 25, p. 79-92, out. 2009.

. Estado, Constituição e administração pública no século XXI: novos desafios da cidadania e do poder local. Belo Horizonte: Arraes, 2017. SANTOS, Boaventura de Souza (Org.). Produzir para viver: os caminhos da produção não capitalista. Rio de Janeiro: Civilização Brasileira, 2002.

As tensões da modernidade. 2005. Disponível em: <http://www.susepe.rs.gov. br/ upload / 1325792284_As \% 20tens \% C3\% B5es \% 20da \% 20Modernidade \% 20-\% 20 Boaventura \%20de\%20Sousa \%20Santos.pdf>. Acesso em: 24 jun. 2018.

SOUZA SANTOS, Boaventura de. Pela mão de Alice: o social e o político na pós-modernidade. 8. ed. São Paulo: Cortez, 2001.

WARAT, Luis Alberto. Por quien cantan las sirenas. Joaçaba: Unoesc/CPGD-UFSC, 1996. 